Artigo Original

\title{
Influência das avós na alimentação de lactentes: o que dizem suas filhas e noras*
}

\author{
Influence of grandmothers on infant feeding: what they say to their daughters and granddaughters
}

Influencia de las abuelas en la alimentación de lactantes: lo que dicen sus hijas y nueras

\section{RESUMO}

Objetivo: Identificar as práticas de primíparas sobre a alimentação de crianças lactentes aprendidas com a mãe e/ou sogra. Métodos: Tratase de pesquisa qualitativa, do tipo descritiva. Os sujeitos foram 11 primíparas, usuárias do Sistema Único de Saúde de Palmeira das Missões/ RS. Os dados foram coletados por entrevista semiestruturada e analisados por meio da análise temática. Resultados: Emergiram três temas: práticas de alimentação transmitidas pelas avós; influência das avós na alimentação do lactente; sentimentos das primíparas em relação às ações das avós relativas à alimentação do lactente. Conclusões: As avós são importantes no que diz respeito à transmissão de conhecimentos, saberes e experiências relativas à alimentação do lactente. Para que a assistência de enfermagem priviligie a autonomia dos sujeitos que envolve corresponsabilidade e congruência cultural, o enfermeiro deve considerar as interações do grupo familiar que, em seu movimento dialético, modulam e são moduladas pela cultura.

Descritores: Aleitamento materno; Cultura; Enfermagem; Família; Nutrição do lactente

\begin{abstract}
Objective: To identify practices of primiparas about infant feeding of infants learned from the mother and/or grandmother. Methods: This was a qualitative, descriptive research study. The subjects were 11 primiparas, who used the Unified Health System of Palmeira das Missões/ RS. Data were collected through semi-structured interviews and analyzed using thematic analysis. Results: Three themes emerged: practices of infant feeding transmitted by grandmothers; influence of grandmothers on infant feeding; feelings of primiparas in regard to the actions of grandmothers on infant feeding. Conclusions: The grandmothers are important with regard to the transmission of knowledge, wisdom and experiences related to infant feeding. For nursing care focused on the subjects' autonomy and responsibility that involves cultural congruence, the nurse should consider that the interactions of the family group, in its dialectical movement, modulate and are modulated by their culture.
\end{abstract}

Keywords: Breast feeding; Culture; Family; Nursing; Infant nutrition

\section{RESUMEN}

Objetivo: Identificar las prácticas de primigestas sobre la alimentación de niños lactantes aprendidas con la madre y/o suegra. Métodos: Se trata de una investigación cualitativa, de tipo descriptiva. Los sujetos fueron 11 primigestas, usuarias del Sistema Único de Salud de Palmeira das Missões/RS. Los datos fueron recolectados por entrevista semiestructurada y analizados por medio del análisis temático. Resultados: Emergieron tres temas: prácticas de alimentación transmitidas por las abuelas; influencia de las abuelas en la alimentación del lactante; sentimientos de las primigestas en relación a las acciones de las abuelas relativas a la alimentación del lactante. Conclusiones: Las abuelas son importantes en lo referente a la transmisión de conocimientos, saberes y experiencias relativas a la alimentación del lactante. Para que la asistencia de enfermería privilegie la autonomía de los sujetos que involucra corresponsabilidad y congruencia cultural, el enfermero debe considerar las interacciones del grupo familiar que, en su movimiento dialéctico, modulan y son moduladas por la cultura.

Descriptores: Lactancia materna; Cultura; Enfermería; Familia; Nutrición del lactante

* Trabalho de Conclusão do Curso de graduação em Enfermagem do Centro de Educação Superior Norte do Rio Grande do Sul da Universidade Federal de Santa Maria - UFSM - Santa Maria (RS), Brasil.

${ }^{1}$ Enfermeira, egressa do Curso de Enfermagem do Centro de Ensino Superior do Norte do Rio Grande do Sul/ Universidade Federal de Santa Maria - UFSM - Santa Maria (RS), Brasil.

${ }^{2}$ Mestre em Enfermagem. Professora do Departamento de Enfermagem do Centro de Ensino Superior do Norte do Rio Grande do Sull Universidade Federal de Santa Maria - UFSM - Santa Maria (RS), Brasil.

${ }^{3}$ Doutora em Enfermagem. Professora do Departamento de Enfermagem da Universidade de Santa Maria - UFSM - Santa Maria (RS), Brasil.

${ }^{4}$ Mestre em Enfermagem. Professora do Departamento de Enfermagem do Centro de Ensino Superior do Norte do Rio Grande do Sull Universidade Federal de Santa Maria - UFSM - Santa Maria (RS), Brasil.

Autor Correspondente: Isabel Cristina Pacheco Van der Sand

Artigo recebido em 05/08/2010 e aprovado em 17/03/2011

R. Angelo Strapazon, 310 Centro - Ijuí - RS - Brasil

Cep: 98700-000 E-mail: isabelvan@gmail.com 


\section{INTRODUÇÃO}

A alimentação ideal para o lactente, até seis meses de vida, é o leite materno de forma exclusiva e após até, no mínimo, dois anos de idade, em associação com outros alimentos $^{(1)}$. Por isso, neste trabalho, quando houver menção ao lactente será referente à criança até dois anos de vida.

Com base nesse entendimento e cientes de que os hábitos alimentares são produzidos no seio da cultura, inicialmente, na família, passamos a nos perguntar se haveria, e de que forma influência da família, em especial, da avó na alimentação do lactente.

A cultura diz respeito a um conjunto de orientações que são herdadas pelos indivíduos que fazem parte de uma sociedade particular, que informam a maneira de ver o mundo, como experimentá-lo emocionalmente e como se comportar em relação às outras pessoas, às forças sobrenaturais e ao ambiente natural. É considerada a "lente" herdada, por meio da qual o indivíduo percebe e compreende o mundo onde habita e aprende a viver dentro dele ${ }^{(2)}$. Além disso, "fornece aos indivíduos um modo de transmitir essas orientações para a próxima geração - pelo uso de símbolos, linguagem, arte e rituais"(2).

Partindo-se do entendimento de que a cultura e o comportamento humano influenciam-se mutuamente e que o enfermeiro, para comunicar-se com o cliente, deve entender sua visão de mundo, crenças, valores e costumes $^{(3)}$ parece-nos importante abordar os fatores que influenciam nas decisões das mulheres em relação à alimentação de seus filhos.

A experiência do aleitamento de um filho é um dos elementos que influencia no processo de alimentação dos demais. A preocupação com a saúde da criança, a praticidade do ato de amamentar, o uso de alimentos considerados lactogogos/galactogogos, as crenças transmitidas por familiares e a maior escolaridade materna são fatores que contribuem para a prática da amamentação ${ }^{(4-\sigma)}$.

Uso de chupeta, acesso ao serviço de saúde privado, primiparidade, idade da mãe inferior a 20 anos, uso de chá no primeiro dia em casa, o não reconhecimento da superioridade da composição do leite humano com introdução de mamadeira, a hipogalactia, complicações mamárias apresentadas pela nutriz são fatores concorrentes ao desmame que, às vezes, se dá antes de um ano de idade ${ }^{(5-}$ 9). A maior escolaridade materna é reconhecida como elemento que concorre para bons índices de aleitamento materno, pois facilita a inserção da mulher no mercado de trabalho, podendo influenciar no desmame precoce ${ }^{(8)}$.

Em relação a fatores de ordem social associados ao aleitamento materno, destaca-se o papel da família. Em alguns estudos, sua influência é apontada como positiva, ocorrendo quando familiares mais velhos, em especial a mãe ou sogra, em virtude da experiência acumulada e do significado que a amamentação tem para essas mulheres, agem como apoiadoras da nutriz no enfrentamento de eventuais problemas relacionados a essa prática ${ }^{(5,10)}$.

Por outro lado, a família também pode influenciar no desmame precoce, pois, conforme não acredita nas qualidades, em especial nutritivas, do leite materno, seus integrantes, e aí incluídas as avós, tendem a aconselhar o uso de chás, água e/ou outro leite, em geral, oferecidos por meio de mamadeira ${ }^{(7,9,11)}$. Portanto, o papel das avós na transmissão de ensinamentos sobre a alimentação da criança e, por consequência, sua influência no desfecho desse evento, varia de acordo com o contexto individual, familiar, social e cultural em que as mulheres estão inseridas.

Percebe-se, que a compreensão dos significados culturais das ações de saúde dispensadas no interior de cada núcleo familiar, entre as quais estão as práticas de alimentação dos lactentes, é importante para guiar a atuação dos profissionais que integram equipes de saúde, em especial, os que atendem à nutriz, o lactente e sua família, buscando ampliar o entendimento a respeito do processo saúde-doença, a fim de implementar ações que superem práticas meramente curativas ${ }^{(12)}$.

Assim, com base nessa percepção e diante da problemática sobre as práticas de alimentação de um lactente e dos fatores que a influenciam, este estudo teve como objetivo geral identificar práticas de primíparas, relativas à alimentação de lactentes, que tenham sido herdadas das avós* (mãe e/ou a sogra). Seus objetivos específicos sintetizam-se em conhecer as ações das avós em relação à alimentação do lactente, na perspectiva da primípara; identificar os sentimentos dessas primíparas em relação às ações das avós relativas à alimentação deste filho; e conhecer a influência das avós sobre a alimentação do lactente.

Em virtude desta investigação ter relação com aspectos da herança cultural sobre a alimentação do lactente lançouse mão, como referencial teórico, do pensamento de enfermeira americana com formação em Antropologia, criadora da Teoria da Universalidade e Diversidade Cultural do Cuidado. Para esta autora, o cuidado universal indica padrões, valores e comportamentos de cuidado que são comuns a todas as culturas. As diversidades de cuidados representam aqueles padrões e processos que são peculiares ou específicos a um indivíduo, família ou grupo cultural ${ }^{(3)}$.

Considerando que as diversidades culturais são em maior número do que os padrões universais de cuidado, os profissionais de enfermagem precisam reconhecer os padrões de saúde e de doença dos indivíduos, as semelhanças e diferenças dos valores, crenças e práticas culturais para, a partir daí, fornecer cuidados culturais congruentes, ou seja, coerentes culturalmente, compreensivos e competentes para pessoas de culturas diferentes ${ }^{(3)}$.

* Sempre que a expressão "avó” ou "avós" for mencionada, refere-se à mãe ou sogra da primípara. 


\section{MÉTODOS}

Este estudo é uma pesquisa de abordagem qualitativa, do tipo descritiva ${ }^{(13-14)}$. Os sujeitos foram 11 primíparas, entre 18 e 29 anos, que atendiam aos seguintes critérios de inclusão: ser mãe de crianças lactentes nascidas a termo (37 a 42 semanas gestacionais), residentes no meio urbano de Palmeira das Missões - RS, usuárias do Sistema Único de Saúde (SUS), que mantinham contato com sua mãe e/ou sogra (nascidas no local do estudo) e que tiveram alta hospitalar por ocasião do parto com seu neonato.

A coleta dos dados deu-se em janeiro e fevereiro de 2010, e o primeiro contato com as possíveis colaboradoras ocorreu em unidades básicas de saúde que oferecem o Programa Nacional de Imunização. Na ocasião, buscouse identificar primíparas que se adequassem aos critérios de inclusão do estudo. Dentre as perguntas feitas nesse momento, questionou-se se haviam recebido orientações de sua mãe e/ou sogra sobre a alimentação do bebê.

Após a identificação, esclareceram-se os objetivos e a metodologia do estudo. Às que aceitaram participar da investigação, realizou-se visita domiciliária, quando os dados foram coletados por meio de entrevista semiestruturada, realizada sempre pela mesma entrevistadora, a partir das questões: conte como foi a alimentação de seu bebê do nascimento até agora. O que sua mãe e/ou sogra a orientou sobre a alimentação de seu bebê? Como você se sente em relação a essas orientações? As entrevistas tiveram duração média de 45 minutos. As informações foram analisadas por meio da análise de conteúdo, mais especificamente a análise temática ${ }^{(13)}$.

Antes da entrevista, os sujeitos assinaram oTermo de Consentimento Livre e Esclarecido, conforme prevê a Resolução n. ${ }^{\text {1 } 196 / 96 ~ d o ~ C o n s e l h o ~ N a c i o n a l ~ d e ~ S a u ́ d e ~}{ }^{(15)}$. O projeto de pesquisa foi aprovado pelo Comitê de Ética em Pesquisa da Universidade Federal de Santa Maria, com o registro CAAE - 0250.0.243.000.0-9.

\section{RESULTADOS}

Diante as 11 primíparas, seis afirmaram ser casadas. Das solteiras, três mencionaram morar com familiares. A escolaridade variou do ensino médio incompleto ao superior completo. Sete primíparas referiram manter atividade fora do lar.

Por meio da análise temática, emergiram três temas, que são explicitados a seguir.

Práticas relacionadas à alimentação de lactentes herdadas das avós

Neste tema, evidencia-se que há uma tendência de valorização do aleitamento materno, como a primeira opção no contexto cultural estudado, alimentação das crianças, inclusive com recomendações, transmitidas de modo intergeracional de práticas que visam a garantir o aleitamento.

As avós aconselharam suas filhas/noras a oferecer o leite materno para seus netos por acreditarem ser o mais adequado para o crescimento e desenvolvimento da criança. Recomendaram que amamentassem o maior tempo possível, de preferência por, no mínimo, seis meses.

"É ela (avó da criança) que me disse que, quanto eu mais pudesse amamentar ele só no peito, até os 6 meses, não dar outra coisa, seria mais saudável pra ele. Que o leite do peito pra criança é um remédio, tipo, não causa doenças, nada nele, dá mais imunidade. Então, foi ela que me incentivou a amamentar ele”. (Ent. 1)

Em alguns casos, em que as primíparas foram acometidas por problemas mamários ou em caso de hipogalactia, as avós, embora incentivassem o aleitamento materno, orientaram e ajudaram suas filhas/noras a dar outros tipos de alimentos ao lactente, como outros leites e alimentos.

"A princípio, ela (avó do lactente) insistiu um pouco pra mim dar o peito, mas como ela viu que eu não ia conseguir, ela também achou melhor que eu desse outro leite". (Ent.7)

A amamentação exclusiva não é uma prática comum no meio estudado, o que, dentre outros fatores, motivase pela prática do uso de chás, especialmente, quando as crianças adoecem. As experiências prévias relativas ao uso de chás, consideradas positivas, influenciam a forma como as avós e as primíparas concebem a alimentação do lactente reproduzindo a ação aprendida, herdada culturalmente.

"Ah, alguma coisinha, chazinho que é bom, calmante que ela é bem agitada assim". (Ent.5)

Dentre as práticas orientadas pelas avós, que visam ao êxito do aleitamento materno, aparecem algumas recomendadas no meio científico, a exemplo de expor a mama à luz solar ou artificial (lâmpada de $40 \mathrm{w}$ ) e evitar sua higienização a cada mamada.

"Eu fazia banbo de luг, que é expor ao sol ou à lu₹, [...] A minha mãe, na primeira semana que eu ganhei bebê, ela ficou comigo e toda noite ela fazia eu fazer, querendo ou não pra não dar... ela já fazía en fazer". (Ent 1)

Durante o processo de lactação, a alimentação da primípara, também é uma preocupação das avós, tendo em vista, entre outros objetivos, o êxito do aleitamento materno. Nesse sentido, as primíparas são aconselhadas 
à ingestão de alguns alimentos que consideram benéficos para essa etapa da vida.

"[...] sempre me diqiam pra comer canjica, bem doce, o que mais... tomar bastante água. [...] Comer pipoca”. (Ent. 4)

As práticas de cuidado visando ao êxito da amamentação são influenciadas por diferentes pessoas do contexto cultural a que pertence a primípara, sejam elas do meio familiar, do sistema profissional ou popular. Estas parecem ser valorizadas e reconhecidas pelas avós, conforme não se contrapõem às mesmas. Tal atitude sugere que a validade das práticas desenvolvidas nesses sistemas é legitimada e transmitida de forma intergeracional. Com base nisso, infere-se que os integrantes desses sistemas constituem-se em importante referência aos sujeitos em suas situações e decisões relativas à saúde e doença.

"Botei a casca de mamão. Só que não adiantou! De certo muito forte, não teve jeito, ele não quis pegar [...] Uma senhora que mora pro lado de cima, uma bem senhora, [...], ela ébenzedeira, [...], mandou eu botar a casca de mamão". (Ent. 9)

"Ah, uma amiga minha, que é enfermeira em [...], ela disse que as compressas de maçanilha eram muito boas. O sachezinho do chá, tu umedecer e colocar no bico do seio, me ajudou bastante junto com as pomadas". (Ent. 5)

Influência das avós na alimentação dos lactentes

Pelos relatos das participantes, pode-se perceber que as avós as orientaram em relação à alimentação de seus filhos, cabendo destacar a aceitação das orientações recebidas.

"Se eu tenho dúvida, a primeira coisa, eu pergunto pra ela se é bom ou se não é, essas coisas assim”. (Ent. 4)

Os resultados do presente estudo evidenciam que a primípara não se opõe em relação às atitudes de sua mãe no que concerne à alimentação de seu filho. Além disso, nem sempre é a avó materna que presta orientações, mas a avó paterna, com evidente reconhecimento por parte da jovem mãe dos cuidados que essa mulher presta ao neto.

"A que teve mais cuidado com a alimentação dela foi a minha sogra, [...], eu trabalhava quando ela era bem pequeninha, en trabalhava só à tarde, daí, de manhã, eu ficava com ela e à tarde ela ficava com a minha sogra. [...] É, ela mora do lado aqui de casa, dai ela cuida [...] Sim, mais que eu até [...], mais que minha mãe também”. (Ent. 5)

Por outro lado, emerge também que nem sempre há concordância entre os desejos da primípara e as atitudes da avó em relação à alimentação do lactente. No entanto, a falta de independência, seja financeira ou emocional, em relação à família de origem, que leva muitas vezes a jovem mãe a residir com as avós da criança, acaba por subordinar suas vontades e crenças em relação ao cuidado de seu filho.

"Porque, às vezes, tem coisa que eu não quero dá e ela dá..," às vezes, ela (avó) tá comendo alguma coisa e ele (bebê) quer e ela dá, tipo bis, coisa assim. [...] Ela que sempre preparava a sopa dele, desde que ele começou a comer, então, ela que sempre fez as comidinhas dele". (Ent. 8)

Sentimentos das primíparas em relação às ações das avós relativas à alimentação do lactente

As primíparas, ao expressarem os sentimentos relativos às orientações que receberam das avós, referem segurança e conforto, o que se justifica pela valorização da experiência acumulada por essas mulheres de seu meio familiar e cultural, que cuidaram de crianças, seja na família ou no trabalho.

"Ah, eu me sinto segura, me sinto mais segura, porque ela já tem experiência, já criou, já cuidou de muitas crianças da viz̧inhança, como o umbigo, essas coisas, primeiro banho, então, a gente se sente bem segura”. (Ent 3)

A vivência anterior das avós é fator que contribui para que as primíparas sintam-se mais seguras em relação à alimentação de seus filhos, mostrando os possíveis sentimentos que podem apresentar nessa fase.

"Eu acho que tudo tu aproveita, tudo que é orientação, informação, acho que tudo, não só da minha mãe, mas de qualquer pessoa que seja experiente, que já teve filho ou que trabalhe com criança, enfim. Eu acho que tudo que vir de informação, que passe orientação, sempre é bem-vindo, é um aprendizado, então". (Ent. 6)

\section{DISCUSSÃO}

De modo semelhante ao primeiro tema do presente estudo, investigação etnográfica sobre crenças e práticas relativas à alimentação do lactente, realizada com mulheres de camadas populares residentes na Região Noroeste do Estado do Rio Grande do Sul, informa que o uso de chás com a finalidade de tratar cólicas do lactente é prática corriqueira naquele cenário cultural, indicada, em geral, pelas avós. No estudo, é destacado a necessidade de negociação cultural entre profissionais e usuários dos serviços de saúde, com a finalidade de evitar-se incongruência cultural e assistência etnocentrista** $^{*}$, com fins de garantir a ressonância das orientações relativas ao aleitamento materno ${ }^{(8)}$.

Em estudo que tem como tema o uso de mamadeira

** O etnocentrismo ocorre quando há uma supervalorização de uma cultura, a exemplo da cultura do subsistema profissional de saúde, em detrimento de outra, ou seja, do subsistema popular. 
no primeiro mês de vida, é apontado que a coabitação com a avó materna associa-se a tal prática, sendo destacado que a maioria das avós estudadas teve seus filhos entre as décadas de 1960 e 1980, quando o aleitamento materno era pouco valorizado. Portanto, de acordo com as autoras, ao recomendarem o uso de chás, água ou até mesmo outro leite, as avós transmitem às suas filhas sua experiência, acreditando ser o mais adequado ${ }^{(7)}$.

Os resultados do presente estudo parecem indicar que há, em certa medida, uma reprodução do discurso científico ou, em outras palavras, há uma aculturação, uma apropriação de elementos de cultura diferente da sua, em geral, mais poderosa ${ }^{(2)}$, o que talvez ocorra em virtude da busca de reconhecimento dos sujeitos do estudo por parte dos profissionais do campo da saúde, aí representados pelo pesquisador na interação com as pessoas no processo de coleta de dados. Tal tendência pode ocorrer em virtude de certa "dogmatização" da ciência em detrimento de conhecimentos de origens outras, a exemplo do senso comum ${ }^{(16)}$, o que contribui para que haja repetição de alguns discursos muitas vezes distantes das práticas cotidianas.

No meio cultural estudado, há estímulo para a ingestão de líquidos, alimentos lácteos e cereais, com ênfase no uso de alimentos adocicados, o que se assemelha a estudo desenvolvido no Maranhão ${ }^{(17)}$. Destaca-se que algumas dessas práticas alimentares são consideradas, em outros estudos de abordagem cultural, com potencial lactogogo ${ }^{(8,10)}$.

Frente a esse resultado, entende-se ser importante considerar que, na assistência de enfermagem à mulher/ mãe que amamenta e sua família, o uso de lactogogos, crença fundamentada nas informações transmitidas culturalmente por meio do relacionamento avó-mãe-filha, representa suporte significativo ao aleitamento materno ${ }^{(4)}$. Assim, somos de opinião que o enfermeiro, que busca apoiar, bem como promover o aleitamento materno necessita que suas ações respeitem e coadunem-se com as crenças culturais dos grupos a quem presta assistência, de forma a contribuir no aumento de autoconfiança das mulheres/mães, sejam elas primíparas ou não, elemento fundamental para o êxito da amamentação.

Nesse sentido, em estudo que tem o objetivo de refletir sobre a implementação do Modelo de Cuidar em Enfermagem com mulheres-avós e sua família em processo de amamentação para a promoção, proteção e apoio ao aleitamento materno no cotidiano familiar, é destacada a necessidade de um repensar, um compartilhar, negociando culturas, de forma a resgatar as ideias de Leininger, que indicam ser necessário envolver, no processo de decisão pela amamentação, a negociação de culturas, entre o cuidado popular e o cuidado profissional sem imposições. É preciso relativizar, mergulhando nas diferentes culturas, o que se mostra com potencial de ressignificação, sem imposições, autoritarismo ou paternalismo ${ }^{(10)}$.

Embora não haja evidências científicas sobre a eficácia de algumas práticas de cuidado utilizadas pelas primíparas deste estudo, a exemplo do uso de casca de mamão em lesões mamilo-areolares, algumas delas são compartilhadas entre os diferentes sistemas de saúde, o que talvez ocorra, no sistema profissional, em decorrência de evidências clínicas. Significa que o enfermeiro, integrante do sistema profissional de saúde, para cuidar, de forma culturalmente congruente, de pessoas com aporte cultural diverso do seu, necessita compreender a visão de mundo, crenças, valores e costumes desses sujeitos, inclusive os fatores que influenciam na determinação e nas decisões em relação ao processo de saúde e de adoecimento. Assim, por meio do diálogo, o enfermeiro necessita compreender os motivos pelos quais são utilizadas determinadas condutas/cuidados, para que, em conjunto e de forma corresponsável, possam conservar, negociar ou repadronizar esses cuidados, conforme preconizado na Teoria da Universalidade e Diversidade Cultural do Cuidado ${ }^{(3)}$.

Por tradição, a mãe exerce a função de eterna orientadora dos atos de sua filha, apesar desta já ter constituído uma família. Esta tradição tem suporte, entre outros determinantes, na vivência da maternidade, que autoriza essa avó a orientar a filha na criação de seus netos, incluídas aí as questões relativas à alimentação dessa criança( ${ }^{(4)}$. Cabe lembrar que a avó materna da criança parece ter maior influência no processo de alimentação do que a avó paterna ${ }^{(7,11)}$, o que é confirmado no presente estudo.

Diante do tema influência das avós na alimentação de lactentes, em estudo realizado com o objetivo de compreender o processo no qual se configura e se sustenta a decisão das mulheres quanto a amamentar ou não seus filhos, é constatado que a mulher, durante o período de amamentação, apresenta-se vulnerável a opiniões e conselhos das pessoas com as quais interage em seu meio, destacando-se o papel das avós, que podem ter influência positiva ou negativa. A influência é negativa quando, em decorrência de sua própria vivência e das informações que receberam à época em que amamentaram, essas avós acreditam que o leite materno é fraco, insuficiente, entre outras situações que depõem contra a amamentação. Mas, em certos casos, algumas avós reconhecem que lhes falta informação sobre aleitamento materno incentivando, mesmo assim a amamentação ${ }^{(18)}$.

Os resultados do presente estudo apontam para associação entre o fato de a primípara morar com a família de origem e o destino da alimentação do lactente. Nesse contexto, estudos que tratam especificamente da relação entre família e puérperas adolescentes, embora não sendo foco específico do presente estudo, oferecem elementos que permitem a compreensão das relações 
estabelecidas no núcleo familiar, visto que apontam para a existência de uma ambivalência no que diz respeito aos benefícios obtidos pelas adolescentes ao morarem com a família de origem após o nascimento do bebê. Por um lado, seria uma forma de proteção, favorecendo uma maternidade positiva e afetuosa. Por outro, muitas vezes, é criado um sistema complexo, instável e conflituoso, relativo aos cuidados dispensados ao bebê, porque nem sempre ocorre uma divisão adequada de tarefas entre a jovem e seus pais. A melhor organização seria o cuidado compartilhado da criança, com a avó não assumindo todas as responsabilidades nem ficando sem se envolver com o bebê $\hat{e}^{(19)}$.

Este estudo sinaliza para a importância de o enfermeiro, ao cuidar da tríade filho-mãe-avó, considerar as relações familiares, o que contribuirá, para que suas ações possam ir ao encontro da dinâmica familiar. A transmissão do conhecimento intergeracional é valorizada no meio estudado, indicando que a experiência é importante no processo de cuidar de uma criança, incluída aí sua alimentação constituindo-se, então, em valor cultural, entendido como um traço particular da cultura estudada ${ }^{(20)}$. A opinião da avó é valorizada por ser ela herdeira de um processo cumulativo de conhecimentos, oriundo de sua convivência com outras pessoas, de sua vivência, adquirida ao longo dos anos, o que a torna reconhecida e respeitada pelos integrantes de seu grupo primário e garante segurança à jovem mãe, quando alimenta seu filho ${ }^{(10)}$.

O reconhecimento desse valor cultural, evidenciado na predisposição a ouvir e levar em consideração a opinião de mulheres mais velhas, no caso em específico em relação às práticas de alimentação das crianças, é importante para o estabelecimento das ações dos profissionais que compõem o sistema profissional de saúde. Nesse contexto, cabe lembrar que as crenças, que são construídas pela interação social, apoiam-se nos valores culturais e experiências vividas, possibilitando que os integrantes de uma família extraiam sentidos e atribuam significados às situações vividas $^{(21)}$. Isso, por consequência, poderá refletir nas decisões sobre a saúde e a doença, incluídos os eventos relativos à alimentação das crianças.

Com base nessa perspectiva, a inclusão dos familiares, em específico das avós, no contexto do cuidado é fundamental, visto que há forte vinculação entre essas mulheres e suas filhas ou noras, sobretudo no que concerne à transmissão de conhecimentos, saberes e experiências. Esta vinculação reveste-se de questões relativas à afetividade, inseridas no cuidado tanto à filha como ao neto. Portanto, consideramos que o conhecimento e as práticas das avós relativas ao processo de alimentação das crianças devem levar em conta o planejamento e a execução de estratégias de cuidado dos profissionais do subsistema profissional de saúde para com a mulher/mãe e o lactente.

\section{CONSIDERAÇÕES FINAIS}

O estudo permite inferir que, no meio analisado, a orientação às filhas e/ou noras sobre a alimentação do lactente faz parte do papel social da avó, cuja experiência constitui-se em valor cultural importante. Além disso, o aleitamento materno é valorizado por parte das avós.

A convivência cotidiana das primíparas estudadas com as avós de seus filhos indica que as interações familiares têm potencialidade para influenciar diretamente nas práticas de cuidados relativos à alimentação da criança. Assim, em relação à alimentação de seus filhos, elas têm possibilidade de fazer como suas mães e/ou sogras ou fazer diferente, o que, por um lado reforça as tradições culturais e, por outro, confere dinamicidade à cultura familiar.

O estudo remete à reflexão sobre a importância de incluir os familiares, no caso em específico as avós, no contexto do cuidado à mulher/mãe e ao lactente, uma vez que nesse meio cultural parece haver uma valorização dos vínculos estabelecidos entre essas mulheres, que favorecem a transmissão intergeracional de conhecimentos, saberes e experiências. Para que se efetive uma assistência de enfermagem que leve em consideração a autonomia dos sujeitos, que se paute na corresponsabilidade e que seja culturalmente congruente, é necessário que o enfermeiro, em sua prática clínica, considere as interações que ocorrem no grupo familiar, as quais, em seu movimento dialético, modulam e são moduladas pela cultura.

Por fim, cabe destacar que este trabalho não se encerra em si, apontando, entre outras possibilidades, para novos estudos que deem voz também às próprias avós a respeito de suas interações com suas filhas/noras nos cuidados relativos à alimentação de seus netos.

\section{REFERÊNCIAS}

1. Rea MF. O pediatra e a amamentação exclusiva. J Pediatr (Rio J). 2003;79(6):479-80.

2. Helman CG. Cultura, saúde e doença. $5 \mathrm{a}$ ed. Porto Alegre: Artmed; 2009. p. 11-25

3. Leininger MM, editor. Culture care diversity and universality: a theory of nursing. New York: National League for Nursing Press; c1991.

4. Ichisato SMT, Shimo AKK. Revisitando o desmame precoce através de recortes da história. Rev Latinoam Enferm. 2002;10(4):578-85.

5. Faleiros FTV, Trezza EMC, Carandina L. Aleitamento materno: fatores de influência na sua decisão e duração. Rev Nutr. 2006;19(5):623-30.

6. Takushi SAM, Tanaka ACA, Gallo PR, Machado MAMP. 
Motivação de gestantes para o aleitamento materno. Rev Nutr. 2008;21(5):491-502.

7. França MCT, Giugliani ERJ, Oliveira LD, Weigert EML, Santo LCE, Köhler CV, Bonilha ALL. Uso de mamadeira no primeiro mês de vida: determinantes e influência na técnica de amamentação. Rev Saúde Pública. 2008;42(4): 607-14.

8. Van der Sand ICP. O bem estar da criança sempre em primeiro lugar: o processo de alimentação do lactente sob a ótica de mulheres-mães de Ijuí-RS [dissertação]. São Paulo: Escola de Enfermagem da Universidade de São Paulo; 1999.

9. Sonego J, Van der Sand ICP, Almeida AM, Gomes FA. Experiência do desmame entre mulheres de uma mesma família. Rev Esc Enferm USP. 2004;38(3):341-9.

10. Teixeira MA, Nitschke RG. Modelo de cuidar em enfermagem junto às mulheres-avós e sua família no cotidiano do processo de amamentação. Texto \& Contexto Enferm. 2008;17(1):183-91.

11. Susin LRO, Giugliani ERJ, Kummer SC. Influência das avós na prática do aleitamento materno. Rev Saúde Pública = J Public Health. 2005;39(2):141-7.

12. Brasil. Ministério da Saúde. Departamento de Atenção Básica. Atenção Básica e a Saúde da Família. Brasília/DF: Ministério da Saúde [Internet]. 2006. [citado 2010 Abr 15] Disponível em: http://dab.saude.gov.br/atencaobasica.php.
13. Minayo MCS. O desafio do conhecimento: pesquisa qualitativa em saúde. 10a. ed. São Paulo: Hucitec; 2007.

14. Gil AC. Como elaborar projetos de pesquisa. 4 a ed. São Paulo: Atlas; 2008.

15. Brasil. Ministério da Saúde. Conselho Nacional de Saúde. Resolução No 196 de 10 de outubro de 1996. Diretrizes e normas regulamentadoras de pesquisa envolvendo seres humanos. Brasil; 1996.

16. Leopardi MT. Metodologia da pesquisa na saúde. 2a ed. Santa Maria: Pallotti; 2002.

17. Sousa FGM, Araujo TL. Padrão alimentar de crianças de 6 a 24 meses em área rural do Maranhão. Acta Paul Enferm. 2005;18(2):172-7.

18. Machado MMT, Bosi MLM.Compreendendo a prática do aleitamento exclusivo: um estudo junto a lactantes usuárias da rede de serviços em Fortaleza, Ceará, Brasil. Rev Bras Saúde Matern Infant. 2008;8(2):187-96.

19. Levandowski DC, Piccinini CA, Lopes RCS. Maternidade adolescente. Estud Psicol (Campinas). 2008;25(2):251-63.

20. Mello LG. Antropologia cultural: iniciação, teoria e temas. 17 a ed. Petrópolis: Vozes; 2009.

21. Girardon-Perlini NMO. Cuidando para manter o mundo da família amparado: a experiência da família rural frente ao câncer [tese]. São Paulo: Escola de Enfermagem da Universidade de São Paulo; 2009. 